\title{
Structure and Nonlinear Optical Properties Study of 2-Amino-5-Chlorobenzophenone: (A Spectroscopic Approach)
}

\section{JESINTHA JOHN ${ }^{1,2}$, D. MANIMARAN ${ }^{1}$, I. HUBERT JOE ${ }^{1 *}$, GEORGE LUKOSE ${ }^{3}$ and SHERIFA RAHIM ${ }^{4}$}

\begin{abstract}
1Department of Physics, Mar Ivanios College, Thiruvananthapuram-695015, Kerala, India. 'Department of Physics, St. Joseph's College for Women, Alappuzha-688001, Kerala, India. ${ }^{3}$ Department of Chemistry, Mar Ivanios College, Thiruvananthapuram-695015, Kerala, India. ${ }^{4}$ Department of Chemistry, St. John's College, Anchal, Kollam-691306, Kerala, India.

*Corresponding author E-mail: hubertjoe@gmail.com
\end{abstract}

http://dx.doi.org/10.13005/ojc/320172

Received: January 13, 2016; Accepted: February 18, 2016

ABSTRACT

The FT-IR and FT-Raman spectra of 2-amino-5-chlorobenzophenone have been recorded and analyzed. Structural geometry, vibrational wavenumbers and first-order hyperpolarizability were computed using density functional theory method. $\mathrm{N}-\mathrm{H} \cdots \mathrm{O}$ distance shows the possibility of intramolecular hydrogen bonding. Natural bond orbital analysis confirms the presence of the $\mathrm{N}-\mathrm{H} \cdots \mathrm{O}$ hydrogen bonding. The computed first-order hyperpolarizability value suggests that 2-amino-5chlorobenzophenone has a potential for producing the second harmonic generation.

Key words: Vibrational spectra, Density functional theory, Natural bond orbital, Hydrogen bonding, Hyperpolarizability.

\section{INTRODUCTION}

Benzophenone, an aromatic ketone (diphenylketone), is an important compound in organic photochemistry which is used as a constituent of synthetic perfumes and as a starting material for the manufacture of dyes, pesticides and drugs and also used as a photo initiator of UVcuring applications in inks, adhesive and coatings, optical fiber as well as in printed circuit boards. It has been the object of many spectral, structural and theoretical investigations because of its interesting chemical and physical properties. Further, the crystals of benzophenones are found to be useful materials for the fabrication of nonlinear optical devices ${ }^{1,2}$. A number of benzophenone derivatives show significantly high second harmonic generation conversion efficiency ${ }^{3-5}$.

The present study deals with the vibrational analysis of 2-amino-5-chlorobenzophenone (2A$5 C B$ ) using density functional theory (DFT) 
calculations ${ }^{6}$ to elucidate the correlation between the molecular structure, nonlinear optical (NLO) property, charge transfer interactions, and first-order hyperpolarizability.

\section{MATERIALS AND METHODS}

The commercially available $2 \mathrm{~A}-5 \mathrm{CB}$ $\left(\mathrm{C}_{13} \mathrm{H}_{10} \mathrm{CINO}\right)$ was purified by repeated recrystallization process using ethanol. Since the solubility of $2 \mathrm{~A}-5 \mathrm{CB}$ is high $\left(10.65 \mathrm{gm} / 100 \mathrm{ml}\right.$ of ethanol at $\left.35^{\circ} \mathrm{C}\right)$ in ethanol, it is easy to grow good quality single crystal. The seed crystals were obtained after three days, among them the defect free and perfectly shaped ones with high transparency were used as the seed crystals for further growth experiment. The seed crystals were first seasoned in the mother solution taken in the Mason jar crystallizer using nylon thread and then allowed to grow into bigger size. The jar was covered with perforated lid to facilitate the slow evaporation of the solvent at a constant temperature of $305 \mathrm{~K}$. Single crystals of size $14 \times 6 \times 5 \mathrm{~mm}^{3}$ are grown in a period of 50-60 days. The crystals tend to grow as needles and appear dark gold in color with good transparency.

$$
I_{i}=\frac{f\left(v_{o}-v_{i}\right)^{4} S_{i}}{v_{i}\left[1-\exp \left(\frac{-h c v_{i}}{k T}\right)\right]}
$$

The room temperature FTIR spectra of the title compound was recorded in the region 4000-400 $\mathrm{cm}^{-1}$ at a resolution of $\pm 1 \mathrm{~cm}^{-1}$, using Bruker IFS 66V vacuum Fourier transform spectrometer, a $\mathrm{KBr}$ beam splitter and globar source. The FT-Raman spectra were recorded on the same instrument with FRA 106 Raman accessories in the region $3500-50 \mathrm{~cm}^{\prime \prime}$. $\mathrm{Nd}$ :YAG laser operating at $200 \mathrm{~mW}$ power with 1064 $\mathrm{nm}$ excitation source.

DFT performed using Gaussian'09 program 7 at the B3LYP level ${ }^{8,9}$, with 6-31G(d) basis set has been used to compute molecular structure and vibrational wavenumbers. For the plots of simulated IR and Raman spectra, pure Lorentzian band shapes were used with full width at half maximum band width of $10 \mathrm{~cm}^{-1}$. The calculated Raman activities were converted to relative Raman intensities using the following relationship derived from the basic theory of Raman scattering ${ }^{10,11}$.

where, $\mu_{\circ}$ is the exciting frequency (in $\mathrm{cm}^{-1}$ ), $\mu_{\mathrm{i}}$ the vibrational wavenumber of the $\mathrm{i}^{\text {th }}$ normal mode, h, c and k, the universal constants and $f$ is the suitably chosen common scaling factor for all the peak intensities.

\section{RESULTS AND DISCUSSION}

\section{Molecular geometry study}

The optimized molecular structure of 2A$5 C B$ was calculated at B3LYP/6-31G(d) level of theory. The optimized molecule structure is shown in Fig. 1. The geometrical parameters are tabulated in Table 1.

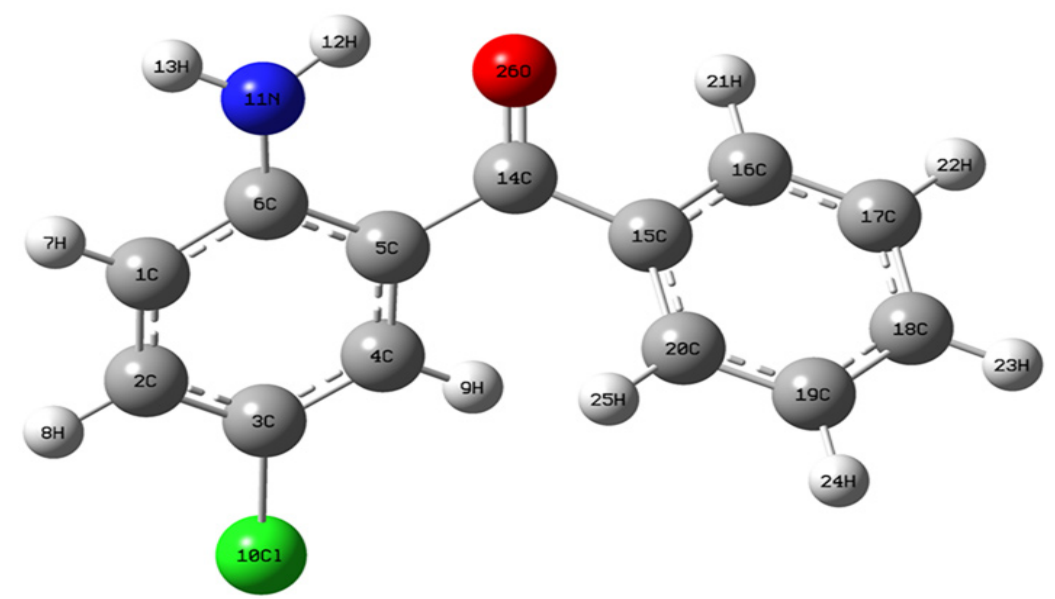

Fig. 1: Optimized structure of $2 \mathrm{~A}-5 \mathrm{CB}$ 
The dihedral angle $\mathrm{C}_{5}-\mathrm{C}_{6}-\mathrm{N}_{11}-\mathrm{H}_{12}$ of the amino group with the phenyl ring 1 shows a deviation of $18.51^{\circ}$ from the plane of the ring. The internal bond angle at the carbon atom to which amino group attached $\left(\mathrm{C}_{1}-\mathrm{C}_{6}-\mathrm{C}_{5}=118.286 \AA\right)$ is consistently smaller than the normally adopted internal bond angle of the phenyl ring. The tri-substituted benzene ring appears a little distorted with $\mathrm{C}_{5}-\mathrm{C}_{6}$ and $\mathrm{C}_{1}-\mathrm{C}_{6}$ bond lengths 1.43118 and $1.41395 \AA$, respectively exactly at the amino group substitution which are longer than $\mathrm{C}_{3}-\mathrm{C}_{4}, \mathrm{C}_{2}-\mathrm{C}_{3}$ and $\mathrm{C}_{1}-\mathrm{C}_{2}$ bond lengths $1.3831,1.40$ and $1.3853 \AA$, respectively. These indicate the resonance effect between the amino group and the phenyl ring1. The bond angle of carbon atom attached to the chlorine atom $\left(\mathrm{C}_{2}-\mathrm{C}_{3}-\right.$ $\mathrm{C}_{4}=120.24 \AA$ ) exceeds the normal value $120^{\circ}$. This is due to the electron donating nature of the chlorine atom.

Table 1: The optimized geometrical parameters of $2 \mathrm{~A}-5 \mathrm{CB}$ at DFT level of theory

\begin{tabular}{|c|c|c|c|c|c|}
\hline \multirow[b]{2}{*}{ Parameters } & \multirow[b]{2}{*}{ value } & \multicolumn{2}{|c|}{ 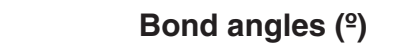 } & \multicolumn{2}{|c|}{ Dihedral angles $(\stackrel{\circ}{)})$} \\
\hline & & Parameters & value & Parameters & value \\
\hline C1-C2 & 1.383 & C1-C2-C3 & 119.6 & C1-C2-C3-C4 & 1.2 \\
\hline C2-C3 & 1.400 & C2-C3-C4 & 120.2 & C2-C3-C4-C5 & -0.25 \\
\hline C3-C4 & 1.383 & C3-C4-C5 & 121.3 & C3-C4-C5-C6 & -1.87 \\
\hline C4-C5 & 1.459 & C4-C5-C6 & 118.8 & $\mathrm{C} 3-\mathrm{C} 2-\mathrm{C} 1-\mathrm{H} 7$ & 179.16 \\
\hline C5-C6 & 1.410 & $\mathrm{C} 2-\mathrm{C} 1-\mathrm{H} 7$ & 119.6 & C4-C3-C2-H8 & -179.61 \\
\hline $\mathrm{C} 1-\mathrm{H} 7$ & 1.087 & C3-C2-H8 & 120.0 & $\mathrm{C} 2-\mathrm{C} 3-\mathrm{C} 4-\mathrm{H} 9$ & -178.69 \\
\hline $\mathrm{C} 2-\mathrm{H} 8$ & 1.085 & C3-C4-H9 & 119.3 & $\mathrm{C} 1-\mathrm{C} 2-\mathrm{C} 3-\mathrm{Cl} 10$ & -178.55 \\
\hline $\mathrm{C} 4-\mathrm{H} 9$ & 1.082 & $\mathrm{C} 2-\mathrm{C} 3-\mathrm{Cl} 10$ & 119.7 & C4-C5-C6-N11 & -179.26 \\
\hline C3-Cl10 & 1.762 & C5-C6-N11 & 121.9 & C5-C6-N11-H12 & 18.51 \\
\hline C6-N11 & 1.365 & C6-N11-H12 & 116.3 & C5-C6-N11-H13 & 168.67 \\
\hline $\mathrm{N} 11-\mathrm{H} 12$ & 1.013 & C6-N11-H13 & 118.2 & C3-C4-C5-C14 & -178.62 \\
\hline $\mathrm{N} 11-\mathrm{H} 13$ & 1.009 & C4-C5-C14 & 120.6 & C4-C5-C14-C15 & -20.89 \\
\hline C5-C14 & 1.483 & C5-C14-C15 & 120.9 & C5-C14-C15-C16 & 145.84 \\
\hline C14-C15 & 1.502 & C14-C15-C16 & 117.8 & C14-C15-C16-C17 & 176.83 \\
\hline C15-C16 & 1.403 & C15-C16-C17 & 120.5 & C15-C16-C17-C18 & -1.55 \\
\hline C16-C17 & 1.391 & C16-C17-C18 & 120.1 & C16-C17-C18-C19 & 0.05 \\
\hline C17-C18 & 1.398 & C17-C18-C19 & 119.9 & C17-C18-C19-C20 & 1.05 \\
\hline C18-C19 & 1.395 & C18-C19-C20 & 120.1 & C18-C17-C16-H21 & 178.33 \\
\hline C19-C20 & 1.395 & $\mathrm{C} 17-\mathrm{C} 16-\mathrm{H} 21$ & 120.8 & C19-C18-C17-H22 & 179.55 \\
\hline $\mathrm{C} 16-\mathrm{H} 21$ & 1.085 & C18-C17-H22 & 120.1 & C16-C17-C18-H23 & -179.51 \\
\hline $\mathrm{C} 17-\mathrm{H} 22$ & 1.086 & C17-C18-H23 & 120.1 & C17-C18-C19-H24 & -178.79 \\
\hline C18-H23 & 1.086 & C18-C19-H24 & 120.2 & C18-C19-C20-H25 & -178.94 \\
\hline C19-H24 & 1.086 & C19-C20-H25 & 119.7 & C16-C15-C14-O26 & -34.25 \\
\hline C2O-H25 & 1.085 & C15-C14-O26 & 117.7 & & \\
\hline C14-O26 & 1.237 & & & & \\
\hline
\end{tabular}

Conjugation of carbonyl group with the phenyl rings would favour a planar conformation, but the steric repulsion between the two ortho hydrogen atoms $\mathrm{H}_{9}$ and $\mathrm{H}_{25}$ prevents the attainment of co-planarity ${ }^{12}$. The two phenyl rings of $2 \mathrm{~A}-5 \mathrm{CB}$ are non-planar with $\mathrm{C}_{6}-\mathrm{C}_{5}-\mathrm{C}_{14}-\mathrm{C}_{15}(162.42 \AA)$ and
$\mathrm{C}_{5}-\mathrm{C}_{14}-\mathrm{C}_{15}-\mathrm{C}_{16}(145.84 \AA)$ dihedral angles. This behaviour has been observed in many structural and spectroscopic studies of diphenyl compounds ${ }^{13}$. The $\mathrm{C}_{5}-\mathrm{C}_{14}(1.483)$ and $\mathrm{C}_{14}-\mathrm{C}_{15}(1.5027 \AA)$ are slightly larger than other $\mathrm{C}-\mathrm{C}$ bonds, indicating negligible conjugation interaction between the two phenyl ring 
systems. The short inter-atomic distance $\mathrm{N}_{11-} \mathrm{H}_{12} \cdots \mathrm{O}_{26}$ reveals the possibility of intramolecular hydrogen bonding.

\section{Potential energy surface scan study}

In order to reveal the minimum energy conformation of the compound, the detailed potential energy surface scan of the dihedral angle $C_{5}-C_{14}-C_{15}-$ $\mathrm{C}_{16}$ is performed. The scan has been carried out by minimizing the potential energy in all geometrical parameters by changing the torsion angle for every $10^{\circ}$ for a $360^{\circ}$ rotation. The shape of the potential energy as a function of the dihedral angle is illustrated in Fig. 2.

The structural studies of tri-substituted benzophenone show approximately equal twist angles of each ring in the range of $20-35^{\circ}$. Hence, a subsequent geometry optimization calculation was carried out by allowing the rotation around the two phenyl rings. From the Fig. 2, it can be shown that the global minimum is observed at $30^{\circ}$. The global minimum energy obtained to be $-1091.61 \mathrm{~kJ} \mathrm{~mol}^{-1}$.

\section{Natural bond orbital analysis}

The natural bond orbital (NBO) analysis provides a description of the structure of a conformer by a set of localized bond, antibonds and Rydberg extra valence orbitals. Stabilizing interactions between filled and unoccupied orbitals and destabilizing interactions between filled orbitals can also be obtained from this analysis ${ }^{14-16}$. Therefore, NBO theory is a valuable complement to the energetic and structural data. DFT level computation is used to investigate the various second order interactions

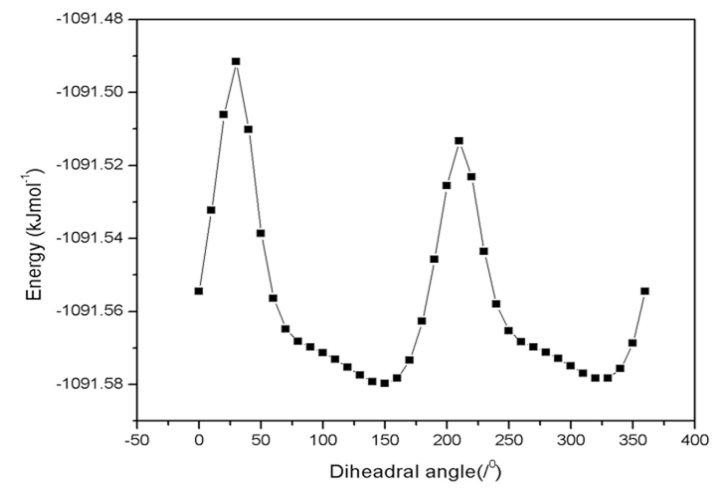

Fig. 2: Potential energy surface scan curve for the dihedral angle $\mathrm{C5}-\mathrm{C} 14-\mathrm{C} 15-\mathrm{C} 16$ between the filled orbitals of one subsystem and the vacant orbitals of another subsystem, which is a measure of delocalization or hyperconjugation ${ }^{17}$. The main natural orbital interactions were analyzed with the NBO 3.1 program ${ }^{18}$. The hyperconjugative interaction energy was deduced from the secondorder perturbation approach.

$$
E(2)=-n_{\sigma} \frac{\langle\sigma|F| \sigma\rangle^{2}}{\varepsilon_{\sigma^{*}}-\varepsilon_{\sigma}}=-n_{\sigma} \frac{F_{i j}^{2}}{\Delta E}
$$

where, $<\sigma|\mathrm{F}| \sigma<$ is the Fock matrix element between $i$ and $j$ NBO orbitals, $\sigma_{s}$ and $n_{\sigma^{*}}$ are the energies of $s$ and $\sigma^{*}$ NBO's, and $n_{\mathrm{s}}$ is the population of the donor s orbital. NBO theory can also be used to identify the hydrogen bonding.

The lowering of orbital energy due to the interaction between doubly occupied orbitals and unoccupied ones is a convenient guide to interpret the molecular structure in the electronic point of view. In energetic terms, hyperconjugation is an important effect in which an occupied Lewis-type natural bond orbital is stabilized by overlapping with a non Lewistype orbital (either one-center Rydberg or two-center antibonding NBO). This electron delocalization can be described as a charge transfer from a Lewis valence orbital (donor), with a decreasing of its occupancy, to a non-Lewis orbital (acceptor). NBO analysis of $2 \mathrm{~A}-5 \mathrm{CB}$ has been performed in order to elucidate the bond effect, intramolecular $\mathrm{N}-\mathrm{H} \cdots \mathrm{O}$ hydrogen bonding and hyperconjugative interaction and the results are shown in the Tables 2 and 3.

The $\mathrm{N}-\mathrm{H} \cdots \mathrm{O}$ hydrogen bonding, in NBO terms, corresponds to the oxygen lone pair and the electron transfer from LP oxygen to the antibonding $(\mathrm{N}-\mathrm{H})$ orbital. The energy lowering corresponding to the interaction between a filled orbital (i) and an antibonding orbital $\left(\mathrm{j}^{\star}\right)$, is deduced from the secondorder perturbation of the filled orbital. Among the most energetic donor-acceptor NBO interactions are those involving the $\mathrm{p}$-type lone pair of the oxygen atom, $\mathrm{LP}_{2} \mathrm{O}_{26}$ with vicinal $\pi^{*}\left(\mathrm{~N}_{11}-\mathrm{H}_{12}\right)$ antibonds having energy contribution $32.3 \mathrm{~kJ} \mathrm{~mol}^{-1}$ of hyperconjugative interaction is weak, these $\mathrm{E}(2)$ values and the low value electron density $(0.5181 \mathrm{e})$ are chemically significant and can be used as a measure of the intramolecular delocalization. The energy values 
corresponding to the charge transfer in the molecules are formed by hydrogen bonding.

The intramolecular hyperconjugative interactions are formed by the orbital overlap between $\pi(\mathrm{C}-\mathrm{C})$ and $\pi^{\star}(\mathrm{C}-\mathrm{C})$ bond orbitals, which results in intramolecular charge transfer (ICT) causing stabilization of the system. These interactions are observed as an increase in ED in $\mathrm{C}-\mathrm{C}$ anti-bonding orbital that weakens their respective bonds. The ED at the six conjugated $\pi(\mathrm{C}-\mathrm{C})$ bonds (1.6-1.7e) and $\pi^{*}$ bonds $(0.213-0.464 \mathrm{e})$ of the phenyl rings clearly demonstrate strong delocalization of electrons leading to a stabilization of energy (80-90 kJ $\left.\mathrm{mol}^{-1}\right)$. This is due to intramolecular charge transfer interaction inside the ring. Among the most energetic donor-acceptor NBO interactions are those involving the $p$-type lone pair of the oxygen atom, $\mathrm{LP}_{1} \mathrm{~N}_{11}$ with $\pi^{\star}\left(\mathrm{C}_{5}-\mathrm{C}_{6}\right)$ antibonds and, $\mathrm{LP}_{3} \mathrm{Cl}_{10}$ with $\pi^{*}\left(\mathrm{C}_{3}-\mathrm{C}_{4}\right)$ having energy contributions 180.71 and $46.52 \mathrm{~kJ}$ $\mathrm{mol}^{-1}$, respectively of hyperconjugative interaction are chemically significant and can be used as a measure of the intramolecular delocalization. A strong interaction has also been observed between the $p$ type orbital containing the lone electron pair of $\mathrm{O}_{26}$ and the neighbourhood anti-bonding orbitals $\sigma^{*}\left(\mathrm{C}_{5}-\mathrm{C}_{14}\right)$ and $\sigma^{*}\left(\mathrm{C}_{14}-\mathrm{C}_{15}\right)$, respectively. This interaction is responsible for hyperconjugation

Table 2: NBO result showing the formation of Lewis and non-Lewis orbitals by the valance hybrids corresponding to the intramolecular $\mathrm{N}-\mathrm{H}$...O

\begin{tabular}{|c|c|c|c|c|c|c|}
\hline Bond(A-B) & ED (a.u) & EDA\% & EDB \% & NBO & $\mathrm{S} \%$ & $\mathbf{P} \%$ \\
\hline \multirow[t]{2}{*}{$\pi \mathrm{C} 18-\mathrm{C} 19$} & 1.6527 & 49.18 & 50.82 & $0.7013(\mathrm{sp} 1.00)_{\mathrm{C}}$ & 0.00 & 99.96 \\
\hline & -0.2495 & - & - & $0.7129(\mathrm{sp} 1.00)_{\mathrm{C}}$ & 0.00 & 99.96 \\
\hline \multirow[t]{2}{*}{$\pi$ C16-C17 } & 1.6559 & 48.56 & 51.44 & $0.7081(\mathrm{sp} 1.81)_{\mathrm{C}}$ & 35.58 & 64.38 \\
\hline & -0.2481 & - & - & $0.7061(\mathrm{sp} 1.83)_{\mathrm{C}}$ & 35.26 & 64.7 \\
\hline \multirow[t]{2}{*}{$\pi$ C15-C20 } & 1.645 & 51.86 & 48.14 & $0.7202($ sp99.99) & 0.01 & 99.96 \\
\hline & -0.2499 & - & - & $0.6938($ sp99.99) & 0.03 & 99.93 \\
\hline \multirow[t]{2}{*}{$\pi \mathrm{C} 14-\mathrm{O} 26$} & 1.9691 & 31.44 & 68.56 & $0.5607(\mathrm{sp} 99.99)$ & 0.03 & 99.8 \\
\hline & -0.3686 & - & - & $0.8280($ sp99.99)。 & 0,04 & 99.68 \\
\hline \multirow[t]{2}{*}{$\pi$ C5-C6 } & 1.5731 & 58.78 & 41.22 & $0.7667(\mathrm{sp} 99.99)$ & 0.01 & 99.98 \\
\hline & -0.2473 & - & - & $0.6420(\mathrm{sp} 1.00)_{\mathrm{C}}$ & 0.00 & 99.96 \\
\hline \multirow[t]{2}{*}{$\pi \mathrm{C} 1-\mathrm{C} 2$} & 1.7277 & 53.9 & 46.1 & $0.7342(\mathrm{sp} 1.00)_{\mathrm{C}}$ & 0.00 & 99.96 \\
\hline & -0.2608 & - & - & $0.6790(\mathrm{sp} 1.00)_{\mathrm{C}}$ & 0.00 & 99.94 \\
\hline \multirow[t]{2}{*}{$\pi \mathrm{C} 3-\mathrm{C} 4$} & 1.7225 & 56.06 & 43.94 & $0.7488(\mathrm{sp} 1.00)_{\mathrm{C}}$ & 0.00 & 99.98 \\
\hline & -0.2702 & - & - & $0.6628(\mathrm{sp} 1.00)_{\mathrm{C}}$ & 0.00 & 99.95 \\
\hline \multirow[t]{2}{*}{$\pi^{\star} \mathrm{C} 3-\mathrm{C} 4$} & 0.3687 & 43.94 & 56.06 & $0.6628(\mathrm{sp} 1.00)_{\mathrm{C}}$ & 0.00 & 99.98 \\
\hline & 0.0194 & - & - & $-0.7488(\mathrm{sp} 1.00)_{\mathrm{C}}$ & 0.00 & 99.95 \\
\hline \multirow[t]{2}{*}{$\pi^{\star} \mathrm{C} 1-\mathrm{C} 2$} & 0.3039 & 46.1 & 53.9 & $0.6790(\mathrm{sp} 1.00)_{\mathrm{c}}$ & 0.00 & 99.96 \\
\hline & 0.0282 & - & - & $-0.7342(\mathrm{sp} 1.00)_{\mathrm{C}}$ & 0.00 & 99.94 \\
\hline \multirow[t]{2}{*}{$\pi^{\star} \mathrm{C} 5-\mathrm{C} 6$} & 0.4642 & 41.22 & 58.78 & $0.6420($ sp99.99) & 0.01 & 99.98 \\
\hline & 0.0191 & - & - & $-0.7667(\mathrm{sp} 1.00)_{\mathrm{C}}$ & 0.00 & 99.96 \\
\hline \multirow[t]{2}{*}{$\pi^{\star} \mathrm{C} 16-\mathrm{C} 17$} & 0.297 & 51.44 & 48.56 & $0.7172(\mathrm{sp} 1.00)_{\mathrm{C}}$ & 0.00 & 99.95 \\
\hline & -0.0363 & & & $-0.6969(\mathrm{sp} 1.00)_{\mathrm{C}}$ & 0.00 & 99.96 \\
\hline \multirow[t]{2}{*}{$\pi^{\star} \mathrm{C} 15-\mathrm{C} 20$} & 0.3658 & 48.14 & 51.86 & $0.6938($ sp99.99) & 0.01 & 99.96 \\
\hline & 0.0313 & - & - & $-0.7202(\mathrm{sp} 99.99)_{\mathrm{C}}$ & 0.03 & 99.93 \\
\hline \multirow[t]{2}{*}{$\pi^{\star} \mathrm{C} 14-\mathrm{O} 26$} & 0.2133 & 68.56 & 31.44 & $0.8280(\mathrm{sp} 99.99)$ & 0.03 & 99.8 \\
\hline & 0.0092 & - & - & $-0.5607(\mathrm{sp} 99.99)_{0}$ & 0.04 & 99.68 \\
\hline \multirow[t]{2}{*}{$\pi^{\star} \mathrm{C} 18-\mathrm{C} 19$} & 0.3213 & 50.82 & 49.18 & $0.7129(\mathrm{sp} 1.00)_{\mathrm{C}}$ & 0.00 & 99.96 \\
\hline & 0.0319 & - & - & $-0.7013(\mathrm{sp} 1.00)_{\mathrm{C}}$ & 0.00 & 99.96 \\
\hline$\pi^{\star} \mathrm{N} 11-\mathrm{H} 12$ & 0.03183 & 26.84 & 73.16 & $0.5181(\mathrm{sp} 2.3)$ & 30.3 & 69.64 \\
\hline
\end{tabular}


between $\mathrm{O}_{26}$ and the ring. These ICT results support the nonlinear optical activity of the molecule.

\section{Vibration spectral analysis}

The observed and calculated wavenumbers together with the calculated IR and Raman intensities are assigned based on potential energy distributions (PED) using VEDA4 program ${ }^{19}$, which are given in table 4 . The observed and simulated vibrational spectra are presented in Figs. 3 and 4. The spectra consists of vibrational patterns originating from the mono and tri-substituted benzene rings and also the

Table 3: Second order perturbation theory analysis of Fock matrix in NBO basis

\begin{tabular}{|c|c|c|c|c|c|c|}
\hline Donor NBO (i) & ED (i) e & Acceptor NBO (j) & $E D(j) e$ & $\begin{array}{c}\mathrm{E}(2) \\
\mathrm{kJ} / \mathrm{mola}\end{array}$ & $\begin{array}{c}E(j)-E(i) \\
k J / \text { mola }\end{array}$ & $\begin{array}{c}F(\mathbf{i}, \mathbf{j}) \\
\mathrm{kJ} / \mathrm{mola}\end{array}$ \\
\hline \multirow[t]{2}{*}{$\pi(\mathrm{C} 1-\mathrm{C} 2)$} & 1.7277 & $\pi^{*}(\mathrm{C} 3-\mathrm{C} 4)$ & 0.36870 & 62.5 & 735.1 & 154.9 \\
\hline & & $\pi^{*}(\mathrm{C} 5-\mathrm{C} 6)$ & 0.46418 & 90.9 & 735.1 & 191.7 \\
\hline \multirow[t]{2}{*}{$\pi(\mathrm{C} 3-\mathrm{C} 4)$} & 1.7225 & $\pi^{\star}(\mathrm{C} 1-\mathrm{C} 2)$ & 0.30394 & 92 & 787.7 & 191.7 \\
\hline & & $\pi^{\star}(\mathrm{C} 5-\mathrm{C} 6)$ & 0.46418 & 52.1 & 761.4 & 147 \\
\hline \multirow[t]{2}{*}{$\pi(\mathrm{C} 5-\mathrm{C} 6)$} & 1.5731 & $\pi^{\star}(\mathrm{C} 1-\mathrm{C} 2)$ & 0.30394 & 58.7 & 735.1 & 149.7 \\
\hline & & $\pi^{\star}(\mathrm{C} 3-\mathrm{C} 4)$ & 0.36870 & 113.2 & 708.9 & 202.2 \\
\hline \multirow[t]{3}{*}{$\pi(\mathrm{C} 15-\mathrm{C} 20)$} & 1.6450 & $\pi^{*}(\mathrm{C} 14-\mathrm{C} 26)$ & 0.21333 & 59.5 & 682.6 & 147 \\
\hline & & $\pi^{\star}(\mathrm{C} 16-\mathrm{C} 17)$ & 0.29702 & 82.2 & 761.4 & 178.5 \\
\hline & & $\pi^{*}(\mathrm{C} 18-\mathrm{C} 19)$ & 0.32134 & 79.9 & 735.1 & 173.3 \\
\hline \multirow[t]{2}{*}{$\pi(\mathrm{C} 16-\mathrm{C} 17)$} & 1.6559 & $\pi^{\star}(\mathrm{C} 15-\mathrm{C} 20)$ & 0.36582 & 81.3 & 735.1 & 173.3 \\
\hline & & $\pi^{*}(\mathrm{C} 18-\mathrm{C} 19)$ & 0.32134 & 88.6 & 735.1 & 181.2 \\
\hline \multirow[t]{2}{*}{$\pi(\mathrm{C} 18-\mathrm{C} 19)$} & 1.6527 & $\pi^{\star}(\mathrm{C} 15-\mathrm{C} 20)$ & 0.36582 & 89.8 & 735.1 & 183.8 \\
\hline & & $\pi^{*}(\mathrm{C} 16-\mathrm{C} 17)$ & 0.29702 & 77.2 & 761.4 & 173.3 \\
\hline LP1 N11 & 1.7538 & $\pi^{*}(\mathrm{C} 5-\mathrm{C} 6)$ & 0.46418 & 180.7 & 761.4 & 275.7 \\
\hline \multirow[t]{3}{*}{ LP2 O26 } & 1.8851 & $\sigma^{\star}(\mathrm{C} 5-\mathrm{C} 14)$ & 0.05521 & 62.8 & 1916.6 & 249.4 \\
\hline & & $\sigma^{*}(\mathrm{C} 14-\mathrm{C} 15)$ & 0.05987 & 77.9 & 1837.9 & 273.1 \\
\hline & & $\sigma^{*}(\mathrm{~N} 11-\mathrm{H} 12)$ & 0.03183 & 32.3 & 1995.4 & 183.8 \\
\hline LP3 Cl10 & 1.9427 & $\pi^{\star}(\mathrm{C} 3-\mathrm{C} 4)$ & 0.36870 & 46.52 & 866.6 & 154.9 \\
\hline
\end{tabular}

${ }^{a} E(2)$ means energy of hyperconjugative interactions (stabilization energy)

${ }^{b}$ Energy difference between donor and acceptor $\mathrm{i}$ and $\mathrm{j}$ NBO orbitals

${ }^{c} \mathrm{~F}(\mathrm{i}, \mathrm{j})$ is the Fock matrix element between $\mathrm{i}$ and $\mathrm{j}$ NBO orbitals

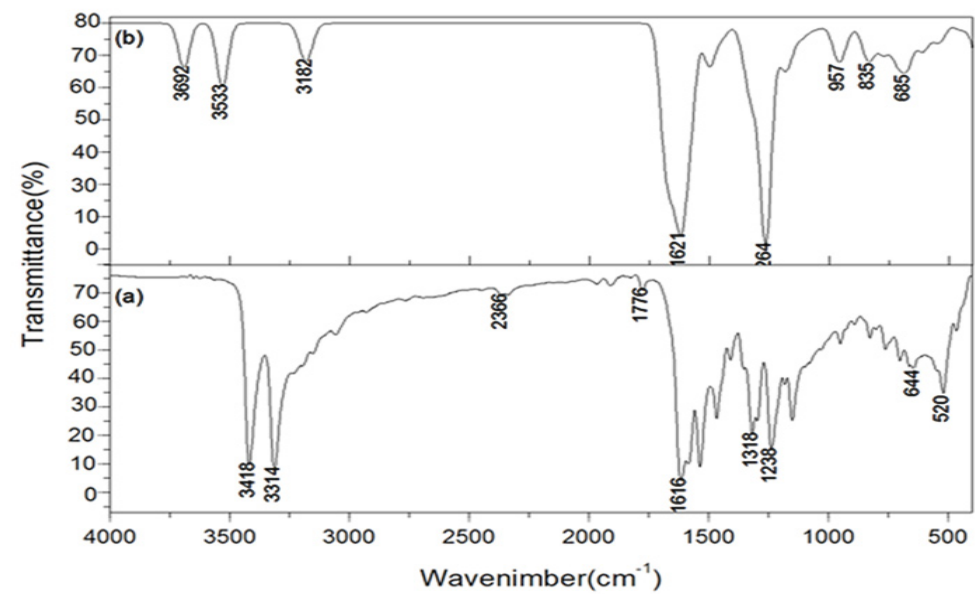

Fig. 3: (a) Experimental (b) simulated infrared spectra of 2A-5CB 


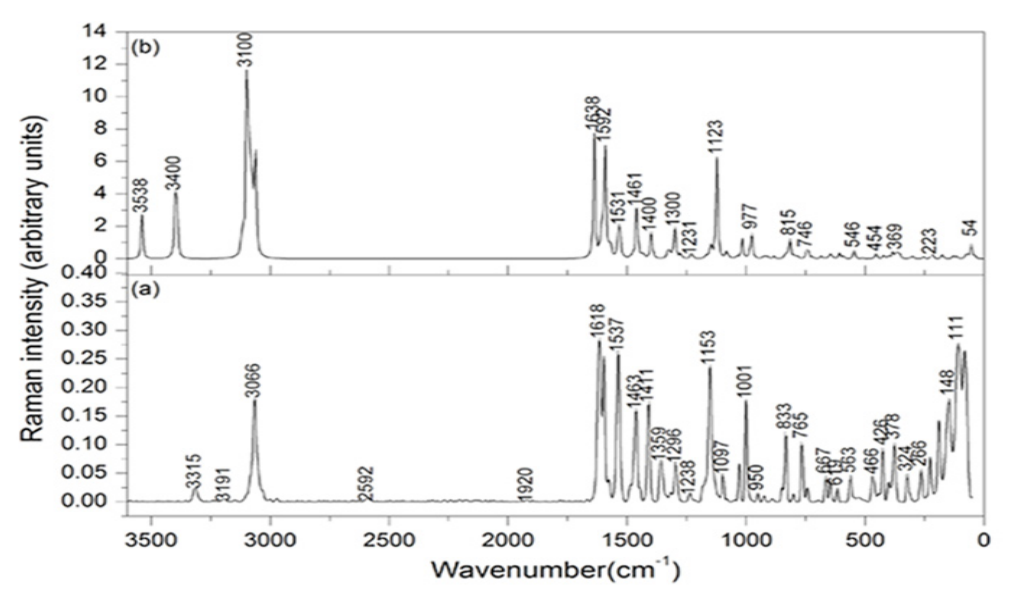

Fig. 4: (a) FT-Raman (b) simulated Raman spectra of 2A-5CB

spectral lines corresponding to $\mathrm{CO}, \mathrm{NH}_{2}$ and $\mathrm{CCl}$ group vibrations that are discussed.

\section{Phenyl ring vibrations}

$2 A-5 C B$ consists of an asymmetrically trisubstituted $\left(\mathrm{Ph}_{1}\right)$ and a mono-substituted benzene ring $\left(\mathrm{Ph}_{2}\right)$. The various normal modes of vibrations of these rings are assigned according to Wilson's numbering convention ${ }^{20,21}$ which are well shown in the calculated DFT level.

An asymmetric tri-substituted aromatic system $\left(\mathrm{Ph}_{1}\right)$ has two adjacent and one isolated $\mathrm{C}-\mathrm{H}$ moieties. The hetero aromatic structure shows the presence of $\mathrm{C}-\mathrm{H}$ stretching vibrations in the region $3100-3000 \mathrm{~cm}^{-1}$, which is the characteristic region for the ready identification of $\mathrm{C}-\mathrm{H}$ stretching vibration which are 2, 20a and 20b modes. Only ring mode 2 is observed in Raman as a weak band at $3191 \mathrm{~cm}^{-1}$ (PED 99\%). The bands 20a and 20b are absent or mixed with other bands and cannot be distinctly observed. These wavenumbers do not correlate with the experimental band position and can be substituted to the intermolecular non bonded interactions. Also ring modes are found to be sensitive to other interactions and the shifting of band position of these modes can be observed. In the case of mono-substituted phenyl ring $\left(\mathrm{Ph}_{2}\right)$, there are five $\mathrm{C}-\mathrm{H}$ stretching vibrations active. They are $2,7 \mathrm{a}, 7 \mathrm{~b}, 20 \mathrm{a}$ and $20 \mathrm{~b}$, which fall in the region $3120-$ $3010 \mathrm{~cm}^{-1}$ 22. The weak shoulder band in IR at 3063 $\mathrm{cm}^{-1}$ and the strong band at $3066 \mathrm{~cm}^{-1}$ in Raman are assigned to the 20a mode, the PED being $87 \%$. Several C-H stretching modes are found to be weak, which are due to the charge transfer between the hydrogen atoms and the carbon atoms ${ }^{23}$.

Normal vibrations $8 \mathrm{a}, 8 \mathrm{~b}, 19 \mathrm{a}, 19 \mathrm{~b}$ and 14 are categorized as $\mathrm{C}-\mathrm{C}$ stretching vibrations in phenyl ring ${ }^{24}$. The mode $8 a$ of the mono-substituted ring vibrations usually appears in the region 1614$1575 \mathrm{~cm}^{-1}$ and $8 \mathrm{~b}$ mode extends around 1597$1562 \mathrm{~cm}^{-1}$. The normal mode $8 \mathrm{a}$ is found at higher wavenumber than $8 \mathrm{~b}$ and appears as a strong band in Raman at $1596 \mathrm{~cm}^{-1}$ (PED 61\%). The mode 8b of the mono-substituted ring $\mathrm{Ph}_{2}$ is also observed in Raman as a weak shoulder band at $1575 \mathrm{~cm}^{-1}$. The vibrational modes 19b, 19a and 14 of ring 1 are computed at 1534, 1459 and $1398 \mathrm{~cm}^{-1}$, respectively and the band at $1326 \mathrm{~cm}^{-1}$ also has contribution from mode 14 . The mode $19 \mathrm{~b}$ is found to be a strong band at 1536 in IR and at $1537 \mathrm{~cm}^{-1}$ in Raman while for 19a, a weak band at $1466 \mathrm{~cm}^{-1}$ in IR and a strong band at $1464 \mathrm{~cm}^{-1}$ are observed. Vibration 14 can be observed as a medium band in IR at $1405 \mathrm{~cm}^{-1}$ and as a strong band in Raman at 1410 and a medium band at $1359 \mathrm{~cm}^{-1}$. The simultaneous appearance of the ring $\mathrm{C}-\mathrm{C}$ stretching bands in both IR and Raman modes of $19 a, 19 b$ and 14 evidence for the charge transfer interactions ${ }^{25,26}$.

The in-plane $\mathrm{CH}$ bending vibrations allowed by the asymmetrically tri-substituted phenyl rings are $3,9 b, 18 b$ and 15 which are computed at 1295 , 1148,1082 and $1148 \mathrm{~cm}^{-1}$, respectively which are in accordance with the previously reported vibrational assignments ${ }^{27}$. The wavenumbers of the above mentioned vibrational modes correlate with the 
Table 4: Vibrational assignments of $2 A-5 C B$ based on potential energy distribution method

\begin{tabular}{|c|c|c|c|c|c|}
\hline \multirow{3}{*}{$v_{\text {calcm }^{-1}}$} & \multicolumn{2}{|c|}{ Calculated } & \multirow{3}{*}{$V_{\mathrm{IR} \mathrm{cm}}^{-1}$} & \multirow{3}{*}{$\begin{array}{c}\text { Experiment } \\
v_{\text {Raman } \mathrm{cm}^{-1}}\end{array}$} & \multirow{3}{*}{ Assignment with PED (\%) } \\
\hline & \multicolumn{2}{|c|}{ Relative Intensity } & & & \\
\hline & IR & Raman & & & \\
\hline 3538 & 63 & 2 & 3418 vs & - & $\mathrm{NH} 2$ asy $\operatorname{str}(100)$ \\
\hline 3396 & 94 & 5 & 3314 vs & $3315 \mathrm{~m}$ & NH2 sym str(100) \\
\hline 3117 & 1 & 1 & - & $3191 w$ & mode 2 of ring 1(99) \\
\hline 3098 & 7 & 4 & - & - & mode $2 e$ of ring2(95) \\
\hline 3097 & 7 & 5 & - & - & mode 2 of ring $1(95)$ \\
\hline 3092 & 12 & 3 & - & - & mode20a of ring $2(80)$ \\
\hline 3083 & 29 & 3 & - & - & mode $20 a$ of ring $2(87)$ \\
\hline 3073 & 10 & 4 & - & - & mode $7 b$ of ring $2(88)$ \\
\hline 3063 & 0 & 1 & 3063 w sh & $3066 v s$ & mode $20 a$ of ring $2(87)$ \\
\hline 3061 & 16 & 3 & - & - & mode $20 a$ of ring $1(95)$ \\
\hline 1638 & 110 & 18 & 1616 vs & $1617 v s$ & $\mathrm{NH} 2$ sci(11),C=Ostr(69) \\
\hline 1609 & 202 & 4 & - & - & mode $8 \mathrm{a}$ of ring $1(44), \mathrm{NH} 2 \mathrm{sci}(25)$ \\
\hline 1594 & 8 & 21 & - & 1596vs & mode $8 a$ of ring $2(61)$ \\
\hline 1574 & 116 & 1 & - & 1575sh & $\mathrm{NH} 2$ rocking(22), mode $8 \mathrm{~b}$ of ring $2(16)$ \\
\hline 1570 & 98 & 2 & - & - & mode $8 b$ of ring $2(24)$ \\
\hline 1534 & 112 & 9 & 1536 vs & 1537vs & mode $19 b$ of ring $1(27)$ \\
\hline 1479 & 3 & 1 & - & - & mode $19 a$ of ring $2(73)$ \\
\hline 1459 & 59 & 11 & 1466 w & $1464 s$ & mode $19 a$ of ring $1(45)$ \\
\hline 1434 & 10 & 1 & - & - & mode $19 a$ of ring $2(63)$ \\
\hline 1398 & 17 & 6 & $1405 \mathrm{~m}$ & $1410 s$ & mode 14 of ring $1(59)$ \\
\hline 1326 & 11 & 3 & - & $1359 \mathrm{~m}$ & mode 14 of ring $1(69)$ \\
\hline 1314 & 3 & 0 & $1318 \mathrm{~s}$ & - & mode 3 of ring $2(79)$ \\
\hline 1300 & 26 & 7 & - & - & mode 3 of ring $1(63)$ \\
\hline 1295 & 17 & 1 & $1291 \mathrm{sh}$ & $1296 \mathrm{~m}$ & mode 3 of ring 2(42), mode 3 of ring $1(29)$ \\
\hline 1275 & 89 & 1 & - & - & mode 3 of ring $1(50)$ \\
\hline 1228 & 337 & 2 & $1238 \mathrm{~s}$ & $1237 w$ & $\begin{array}{l}\mathrm{C}_{4}-\mathrm{C}_{5} \operatorname{str}(11), \mathrm{C}_{5}-\mathrm{C}_{14} \operatorname{str}(29) \\
\mathrm{H}_{9}-\mathrm{C}_{4}-\mathrm{C}_{5} \text { bend }(22)\end{array}$ \\
\hline 1167 & 23 & 1 & $1181 \mathrm{~m}$ & - & mode $9 a$ of ring $2(89)$ \\
\hline 1149 & 4 & 3 & - & - & $\begin{array}{l}\text { mode } 15 \text { of ring } 1(56) \text {, mode } 15 \text { of } \\
\text { ring } 2(12)\end{array}$ \\
\hline 1148 & 29 & 2 & $1150 \mathrm{~m}$ & 1153vs & $\begin{array}{l}\text { mode } 9 b \text { of ring } 1(56) \text {, mode } 9 a \text { of } \\
\text { ring } 2(66)\end{array}$ \\
\hline 1123 & 30 & 26 & - & - & $\begin{array}{l}\text { C5-C14 str(19), mode } 19 a \text { of ring } 2(11) \text {, } \\
\text { mode } 19 \text { a of ring1(16) }\end{array}$ \\
\hline 1082 & 12 & 2 & - & $1097 \mathrm{~m}$ & mode $18 b$ of ring $1(69)$ \\
\hline 1072 & 6 & 0 & - & - & mode15 of ring $2(78)$ \\
\hline 1039 & 6 & 1 & - & $1029 m$ & H12- N11-C6 bend(44) \\
\hline 1016 & 3 & 6 & - & $1001 \mathrm{~s}$ & mode $18 a$ of ring $2(82)$ \\
\hline 979 & 2 & 10 & - & - & mode 12 of ring $2(60)$ \\
\hline 965 & 0 & 0 & - & - & mode 5 of ring 2(81) \\
\hline 943 & 3 & 0 & 946 w & $951 w$ & mode 5 of ring $2(93)$ \\
\hline 926 & 46 & 1 & - & $925 w$ & mode $17 \mathrm{~b}$ of ring $1(42)$, mode $17 \mathrm{~b}$ \\
\hline
\end{tabular}




\begin{tabular}{|c|c|c|c|c|c|}
\hline & & & & & \\
\hline 917 & 0 & 0 & - & - & mode $17 a$ of ring $1(82)$ \\
\hline 910 & 10 & 1 & - & - & $\begin{array}{l}\text { mode } 10 \mathrm{~b} \text { of ring } 2(56) \text {, mode } 10 \mathrm{~b} \text { of } \\
\text { ring } 1(11)\end{array}$ \\
\hline 884 & 12 & 1 & 889 w & $888 w$ & mode $10 a$ of ring $1(78)$ \\
\hline 834 & 3 & 2 & $826 s$ & $833 s$ & mode $10 a$ of ring $2(87)$ \\
\hline 817 & 21 & 9 & - & - & mode $10 a$ of ring $1(36)$ \\
\hline 797 & 30 & 1 & $801 w$ & $801 w$ & mode 6 of ring $1(66)$ \\
\hline 786 & 10 & 1 & $762 \mathrm{w}$ & $766 s$ & $\begin{array}{l}\text { mode } 10 a \text { of ring } 1(20) \text {, mode } 10 a \text { of ring } \\
2(12), O_{26}-C_{5}-C_{15}-C_{14} \text { out(31) }\end{array}$ \\
\hline 743 & 36 & 7 & - & $743 w$ & mode $10 a$ of ring1(13) \\
\hline 723 & 18 & 1 & - & - & mode $10 a$ of ring $2(27)$ \\
\hline 686 & 30 & 1 & 700 w & - & mode 11 of ring $2(84)$ \\
\hline 671 & 5 & 0 & 660 w & $666 \mathrm{~m}$ & $\begin{array}{l}\text { mode } 6 \mathrm{~b} \text { of ring } 1(32) \text {, mode } 6 \mathrm{~b} \text { of ring } \\
2(13), \mathrm{O}_{26}-\mathrm{C}_{5}-\mathrm{C}_{15}-\mathrm{C}_{14} \text { out(12) }\end{array}$ \\
\hline 648 & 37 & 3 & 644 w & $648 w$ & $\begin{array}{l}\text { mode } 6 a \text { of ring } 1(11) \text {, mode } 6 a \\
\text { of ring } 2(23)\end{array}$ \\
\hline 636 & 20 & 1 & - & $618 w$ & mode $6 a$ of ring $1(43), C_{3}-C_{10} \operatorname{str}(10)$ \\
\hline 608 & 0 & 3 & - & - & mode $6 \mathrm{~b}$ of ring $2(83)$ \\
\hline 591 & 69 & 2 & - & $562 \mathrm{~m}$ & $\mathrm{H}_{12}-\mathrm{N}_{11}-\mathrm{C}_{6}-\mathrm{C}_{1} \operatorname{tor}(75)$ \\
\hline 546 & 8 & 5 & - & - & mode 4 of ring $1(22)$, mode 4 of ring $2(11)$ \\
\hline 513 & 17 & 1 & $520 \mathrm{~m}$ & - & mode $16 \mathrm{~b}$ of ring $1(62)$ \\
\hline 454 & 8 & 4 & $468 w$ & $467 \mathrm{~m}$ & $\mathrm{~N}_{11}-\mathrm{C}_{6}-\mathrm{C}_{1}$ bend $(60)$ \\
\hline 437 & 13 & 0 & - & - & mode $16 \mathrm{~b}$ of ring $1(49)$ \\
\hline 421 & 4 & 3 & - & $426 m$ & mode $16 b$ of ring $1(33)$ \\
\hline 403 & 3 & 3 & - & 408sh & mode $16 a$ of ring $2(86)$ \\
\hline 385 & 50 & 5 & - & - & $\mathrm{C}_{2} \mathrm{C}_{3}-\mathrm{C}_{4}$ bend(36) \\
\hline 371 & 123 & 7 & - & $378 m$ & $\mathrm{C}_{3}-\mathrm{Cl}_{10} \operatorname{str}(17), \mathrm{H}_{13}-\mathrm{N}_{11}-\mathrm{C}_{6}-\mathrm{C}_{5}$ tor(42) \\
\hline 358 & 53 & 8 & - & - & $\mathrm{C}_{3}-\mathrm{Cl}_{10} \operatorname{str}(26), \mathrm{H}_{13}-\mathrm{N}_{11}-\mathrm{C}_{6}-\mathrm{C}_{5} \operatorname{tor}(25)$ \\
\hline 312 & 4 & 1 & - & $323 m$ & mode $16 \mathrm{~b}$ of ring $1(60)$ \\
\hline 301 & 7 & 3 & - & - & $\mathrm{Cl}_{10}-\mathrm{C}_{3}-\mathrm{C}_{4}$ bend $(60)$ \\
\hline 255 & 0 & 3 & - & $265 \mathrm{~m}$ & $\mathrm{C}_{5}-\mathrm{C}_{14} \operatorname{str}(39)$ \\
\hline 218 & 1 & 10 & - & $227 m$ & $\mathrm{C}_{4}-\mathrm{C}_{5}-\mathrm{C}_{14}-\mathrm{C}_{15}$ tor(12), $\mathrm{C}_{4}-\mathrm{C}_{3}-\mathrm{Cl}_{10}(48)$ \\
\hline 175 & 1 & 9 & - & $190 m$ & $\begin{array}{l}\mathrm{Cl}_{10}-\mathrm{C}_{3}-\mathrm{C}_{4} \text { bend(18), } \mathrm{C}_{14}-\mathrm{C}_{16}-\mathrm{C}_{20}-\mathrm{C}_{15} \\
\text { out(11), } \mathrm{C}_{4}-\mathrm{C}_{5}-\mathrm{C}_{14} \text { bend }(29)\end{array}$ \\
\hline 129 & 3 & 9 & - & $149 s$ & $\mathrm{C}_{14}-\mathrm{C}_{16}-\mathrm{C}_{20}-\mathrm{C}_{15}$ out $(66)$ \\
\hline 115 & 1 & 6 & - & $111 v s$ & $\mathrm{C}_{1}-\mathrm{C}_{2}-\mathrm{C}_{3}-\mathrm{C}_{4}$ tor $(79)$ \\
\hline 73 & 0 & 36 & - & $82 \mathrm{~s}$ & $\begin{array}{l}\mathrm{C}_{14}-\mathrm{C}_{16}-\mathrm{C}_{20}-\mathrm{C}_{15} \text { out }(38), \mathrm{C}_{4}-\mathrm{C}_{3}-\mathrm{Cl}_{10} \\
\text { bend(30) }\end{array}$ \\
\hline 54 & 0 & 100 & - & - & $\mathrm{C}_{4}-\mathrm{C}_{5}-\mathrm{C}_{14}-\mathrm{C}_{15}$ tor(60), $\mathrm{C}_{4}-\mathrm{C}_{3}-\mathrm{Cl}_{10}$ bend(12) \\
\hline 39 & 1 & 34 & - & - & $\mathrm{C}_{1}-\mathrm{C}_{2}-\mathrm{C}_{3}-\mathrm{C}_{4}$ tor(82) \\
\hline
\end{tabular}

vs-very strong; s-strong; m-medium; sh-shoulder; w-weak; vw-very weak; ring-phenyl ring; str-stretching; bend-bending; tor-torsion; sci-scissoring; wag-wagging; sym-symmetric; asy- asymmetric; out - out-of-plane bending

cOnly PED values greater than $10 \%$ are given. 
experimental values except the mode at $1148 \mathrm{~cm}^{-1}$. The mode 3 is found to be a medium band in Raman at $1296 \mathrm{~cm}^{-1}$ and that in IR as a shoulder band at $1291 \mathrm{~cm}^{-1}$. The mode $9 \mathrm{~b}$ of ring 1 is found to be strong in Raman at $1153 \mathrm{~cm}^{-1}$ and that in IR as a medium band at $1150 \mathrm{~cm}^{-1}$ (PED 56\%). The mode $18 \mathrm{~b}$ of the ring1 is found only in Raman as a medium band at $1097 \mathrm{~cm}^{-1}$. The normal modes 3, 9a, 5, 18a and $18 \mathrm{~b}$ are classified as $\mathrm{CH}$ in-plane bending vibrations in mono-substituted benzene rings. The bands observed at $1291 \mathrm{~cm}^{-1}$ in IR and that at $1296 \mathrm{~cm}^{-1}$ in Raman are assigned to the mode 3 of $\mathrm{Ph}_{2}$. The vibrational mode $9 \mathrm{a}$ is observed as a medium band in IR at $1150 \mathrm{~cm}^{-1}$ and Raman at $1153 \mathrm{~cm}^{-1}$ (PED $66 \%$ ) as a strong band. The mode 18 a occurs as a strong band in Raman at $1001 \mathrm{~cm}^{-1}$ (PED 82\%).

The $\mathrm{C}-\mathrm{H}$ out-of-plane bending of phenyl ring 1 are computed at 925 and $743 \mathrm{~cm}^{-1}$ for $17 \mathrm{~b}$ and 11 modes, respectively and the computed values correlate well with the experimental band positions showing that the $\mathrm{C}-\mathrm{H}$ out-of-plane bending modes are less influenced by intermolecular interactions. The out-of-plane skeletal mode $6 \mathrm{a}$ of ring1 and 2 are found at 644 in IR and $648 \mathrm{~cm}^{-1}$ in Raman as weak bands. The $\mathrm{C}-\mathrm{H}$ out-of-plane bending $(5,10 \mathrm{a}$, $10 \mathrm{~b}, 11,17 \mathrm{a})$, radial skeletal $(1,12,6 \mathrm{a}$ and $6 \mathrm{~b})$ and the out-of-plane skeletal $(4,16 a$ and 16b) of Ph2 vibrations are also listed in table 4.

\section{$\mathbf{C}=\mathbf{O}$ vibrations}

The benzophenone skeleton forms the tripod that has $\mathrm{C}=\mathrm{O}$ bond as one branch and other two branches are formed from phenyl rings. Because of the different electro-negativities of carbon and oxygen atoms, the bonding electrons are not equally distributed between the two atoms. The lone pair of electrons on oxygen also determines the nature of the carbonyl group ${ }^{28}$. In the vibrational assignments of aromatic and aryl aliphatic ketones, Kolev ${ }^{29}$ observed the bands of $i(C=O)$ for 14 different aromatic and aryl aliphatic ketones. The $\mathrm{C}=\mathrm{O}$ stretching vibrations give rise to the characteristic bands in IR and Raman and the intensity of these bands can increase owing to the conjugation or formation of hydrogen bonds. The $\mathrm{C}=\mathrm{O}$ stretching of ketones are expected in the region $1760-1730 \mathrm{~cm}^{\prime 1}$. A strong intense and well defined peak observed in Raman at $1617 \mathrm{~cm}^{-1}$ is due to the $\mathrm{C}=\mathrm{O}$ stretching vibration of the carbonyl group. Similarly a highly intense band is observed at 1616 $\mathrm{cm}^{-1}$ in IR also due to $\mathrm{C}=\mathrm{O}$ stretching (PED 69\%). The lowering of $\mathrm{C}=\mathrm{O}$ stretching wavenumber is due to the conjugation between the carbonyl group and the aromatic ring and also due to the formation of hydrogen bonding.

\section{Amino group vibrations}

The amino group is generally referred to as an electron donating substituent in aromatic ring system. The asymmetric interaction between the amino group and the aromatic ring produce a small displacement of the $\mathrm{N}$-atom out of the benzene ring. In the region $3700-3300 \mathrm{~cm}^{-1}$, only two bands are observed. The higher wavenumber band which is intense in the IR spectrum $\left(3418 \mathrm{~cm}^{-1}\right)$ has been assigned to asymmetric stretching (PED100\%) in amino group vibration. The intense band in IR spectrum $\left(3314 \mathrm{~cm}^{-1}\right)$ and the medium band in Raman $\left(3315 \mathrm{~cm}^{-1}\right)$ have been assigned to symmetric stretching (PED100\%) of amino group vibrations. These assignments find support from the work of other researchers in the case of related molecules ${ }^{30}$. These wavenumbers and the ratio of intensities of the two bands are characteristic of $\mathrm{NH}_{2}$ stretching mode. The lowering of $\mathrm{NH}$ stretching wavenumber is due to intermolecular $\mathrm{N}-\mathrm{H} \cdots \mathrm{O}$ interaction. The redshifting of wavenumber in the $\mathrm{NH}$ bond order value is occurring due to donor-acceptor interactions. The $\mathrm{NH}_{2}$ stretching vibrations show the characteristic wavenumber shift caused by the halogen substituent also. Due to the low symmetry of the molecule, several internal coordinates also contribute to each normal mode. The $\mathrm{NH}$ scissoring deformation of amino groups appear around $1610-1630 \mathrm{~cm}^{\mathrm{I1}}$ and the rocking deformation around $1070-1050 \mathrm{~cm}^{-1} 22$. The bands observed at 1617 and $1616 \mathrm{~cm}^{-1}$ in Raman and IR were assigned to the scissoring modes of $\mathrm{NH}_{2}$ group. The band identified at $1575 \mathrm{~cm}^{-1}$ in Raman was assigned to the rocking mode.

\section{$\mathrm{CCl}$ vibrations}

The vibrations belonging to the bond between the ring and the halogen atoms are worth to discuss here, since mixing of vibrations are possible due to the lowering of the molecular symmetry and the presence of heavy atoms on the periphery of the molecule ${ }^{31}$. The assignments of $\mathrm{CCl}$ stretching and deformation vibrations have been made by comparison with similar molecules, para-bromophenol ${ }^{32}$ and the halogen-substituted 
benzene derivatives ${ }^{33}$ assigned vibrations of $\mathrm{C}-\mathrm{X}$ group $(\mathrm{X}=\mathrm{Cl}, \mathrm{Br}$ and $\mathrm{I})$ in the wavenumber range of $1129-480 \mathrm{~cm}^{-1}$. Normally the $\mathrm{CCl}$ stretching bands are expected around 1060-395 $\mathrm{cm}^{-1}{ }^{34}$. In the $2 \mathrm{~A}$ $5 C B$ a weak Raman band at $618 \mathrm{~cm}^{11}$ is assigned to $\mathrm{CCl}$ stretching vibration. A medium band at $227 \mathrm{~cm}^{\prime \prime 1}$ (PED 48\%) and a strong Raman band at $82 \mathrm{~cm}^{\prime \prime} 1$ (PED 30\%) are assigned to $\mathrm{CCl}$ bending vibrations, which are coupled with C-C-C vibrations.

\section{Nonlinear optical property analysis}

Polarizability characterizes the ability of an electric field to distort the electronic distribution of a molecule. Higher order polarizabilities (hyperpolarizabilities $\beta, \gamma$ ) which describe the nonlinear response of atoms and molecules are related to a wide range of phenomenon from nonlinear optics to intermolecular forces, such as the stability of chemical bonds as well as the conformation of molecules and molecular aggregates ${ }^{35}$. These studies led to the fact that $a b$ initio calculations of polarizabilities and hyperpolarizabilities have become available through the strong theoretical basis for analyzing molecular interactions. They made possible for the determination of the elements of these tensors from derivatives of the dipole moment with respect to the electric field. Since polarizabilities and hyperpolarizabilities are derivatives of the molecular energy with respect to the strength of the applied electric field, their theoretically calculated values may be sensitive to basis-sets and the levels of theoretical approach employed and the electron correlation can change the values of hyperpolarizabilities ${ }^{36-40}$. Even order hyperpolarizabilities are zero, vanishing for systems with inversion symmetry. However, in the present case the situation differs since, $2 \mathrm{~A}-5 \mathrm{CB}$ is a non-centrosymmetric molecule possessing a permanent dipole moment, where the polarization response to an external electric field of fixed strength dominated by the $\pi$-electrons found that the origin of the nonlinearity is to be sought not only in the independent bonds formed by the ó electrons which

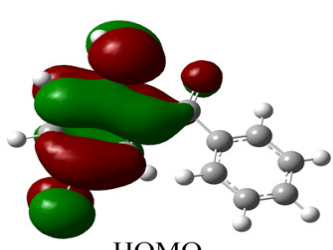

HOMO

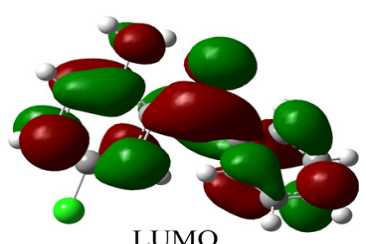

LUMO
Fig. 5: HOMO and LUMO plots of $2 \mathrm{~A}-5 \mathrm{CB}$ contribute linearly, but in the delocalized $ठ$ electron cloud.

The static hyperpolarizability $\left(\beta_{0}\right)$ and it's related properties $\left(\beta, \alpha_{0}\right.$ and $\left.\Delta a\right)$ have been calculated on the basis of the finite-field approach. In the presence of an applied electric field the first-order hyperpolarizability is a third rank tensor that can be described by a $3 \times 3 \times 3$ matrix. The components of $b$ are defined as the coefficients in the Taylor series expansion of the energy in the external electric field. When the external electric field is weak and homogeneous, the expansion becomes.

$E=E^{0}-\mu_{\alpha} F_{\alpha}-1 / 2 \alpha_{\alpha \beta} F_{\alpha} F_{\beta}-1 / 6 \beta_{\alpha \beta \gamma} F_{\alpha} F_{\beta} F_{\gamma}+\ldots$

where, $E^{0}$ is the energy of the unperturbed molecules, $F_{\alpha}$ is the field at the origin $\mu_{\alpha}, \alpha_{\alpha \beta}$ and $\beta_{\alpha \beta \gamma}$ are the components of dipole moment, polarizability and the first-order hyperpolarizability, respectively. From this, the first-order hyperpolarizability $\left(\beta_{0}\right)$ using the $x, y, z$ component is defined as

$$
\beta_{0}=\left(\beta_{x}^{2}+\left(\beta_{y}^{2}+\beta_{z}{ }^{2}\right)^{1 / 2}\right.
$$

The calculated first-order hyperpolarizability of $2 \mathrm{~A}-5 \mathrm{CB}$ is $1.53 \times 10^{-30}$ e.s.u., which is 6 times greater than that of urea. From the computation, the high values of the hyperpolarizabilities of $2 A-5 C B$ are probably attributed to the charge transfer existing between the phenyl rings within the molecular skeleton. This is the evidence for nonlinear optical property of the molecule. The analysis of the wave function indicates that the electronic absorption corresponds to the transition from the ground to the first excited state and is mainly described by one-electron excitation from the highest occupied molecular orbital (HOMO) to the lowest unoccupied molecular orbital (LUMO). The atomic orbital compositions of the frontier molecular orbitals are sketched in Fig. 5. The HOMO energy $=-8.19 \mathrm{eV}$, LUMO energy $=-5.92 \mathrm{eV}$ and HOMO-LUMO energy gap $=2.2 \mathrm{eV}$. In addition, the decrease in HOMO and LUMO energy gap explains the eventual charge transfer interaction taking place within the molecule which is responsible for the NLO activity.

Analysis of organic molecules having conjugated $\delta$-electron systems and large 
hyperpolarizability using IR and Raman has been evolved as a subject of recent research ${ }^{41}$. The potential applications of $2 A-5 C B$ in the field of nonlinear optics demands the investigation of its structural and bonding features contributing to the hyperpolarizability enhancement by analyzing the vibrational modes using the IR and Raman spectra. The selection rule predicts the splitting of vibrational mode 19 (19a and 19b) in substituted phenyl rings. The modes $19 \mathrm{a}, 19 \mathrm{~b}$ and 14 are active in both IR and in Raman simultaneously and their relative intensities are comparable which gives the evidence of the charge transfer from the donor to the acceptor group via the conjugated path, inducing charge variations in dipole moment and polarizability.

The $\mathrm{C}=\mathrm{O}$ stretching vibrations give rise to the characteristic bands in the IR and Raman, and intensity of these bands can increase owing to the conjugation of formation of hydrogen bonds. The lowering of carbonyl stretching wavenumber is also contributed by the electron releasing effect of the $\mathrm{C}=\mathrm{O}$ bond in the acceptor unit owing to intramolecular charge transfer as reported earlier ${ }^{42}$ in addition to the intermolecular effect and $\delta$-conjugation. Electron releasing effect in the $\mathrm{C}=\mathrm{O}$ double bond causes polarizability change during vibration, making the Raman band also strong whose intensity is comparable to that of IR band.

\section{CONCLUSION}

The red-shift of the $\mathrm{NH}$ stretching wavenumber in the infrared spectrum indicates the presence of $\mathrm{N}-\mathrm{H} \cdots \mathrm{O}$ bonding, resulting in proton transfer which increases the molecular hyperpolarizability of the material. The $\mathrm{N}-\mathrm{H} \cdots \mathrm{O}$ hydrogen bonding network and the intramolecular charge transfer interaction has been analyzed using NBO analysis. The ð-electron delocalization over the carbazone moiety is responsible for the nonlinearity of the molecule. The simultaneous activation of the mode 19 supports the charge transfer interaction. The calculated firstorder hyperpolarizability of $2 A-5 C B$ is to be $1.53 x$ $10^{-30}$ e.s.u. The enhancement of hyperpolarizability value and the lowering of HOMO-LUMO energy gap confirms charge transfer interaction arise in the molecule.

\section{ACKNOWLEDGEMENT}

Prof. Micha ${ }^{3} \mathrm{H}$. Jamróz, Institute of Nuclear Chemistry and Technology, Warsaw, Poland for providing VEDA4 program.

\section{REFERENCES}

1. Vul, E.B.; Lobanova, G.M. Kristallografiya. 1967, 12, 411-413.

2. Fleischer, E.B.; Sung, N.; Hawkinson, S. J. Phys. Chem. 1968, 72, 4311-4312.

3. Babu, G.A;Thirupugalmani, K.; Jayaprakasan, M.; Ramasamy, P. J. Cryst. Growth. 2009, 311, 1607-1611.

4. Babu, G.A.; Ramasamy, P. Mater. Chem. Phys. 2010, 119, 533-538.

5. Genbo, S.; Shouwu, G.; Feng, P.; Youping, H.; Zhengdong, L. J. Phys. D: Appl. Phys. B. 1993, 26, 236-237.

6. Rauhut, G.; Pulay, P. J. Phys. Chem. 1995, 99, 3093-3100.

7. Frisch, M. J.; Trucks, G. W.; Schlegel, H. B.; Scuseria, G. E.; Robb, M. A.; Cheeseman, J. R.; Scalmani, G.; Barone, V.; Mennucci, B.; Petersson, G. A.; Nakatsuji, H.; Caricato, M.; Li, X.; Hratchian, H. P.; Izmaylov, A. F.;
Bloino, J.; Zheng, G.; Sonnenberg, J. L.; Hada, M.; Ehara, M.; Toyota, K.; Fukuda, R.; Hasegawa, J.; Ishida, M.; Nakajima, T.; Honda, Y.; Kitao, O.; Nakai, H.; Vreven, T.; Montgomery, J. A., Jr.; Peralta, J. E.; Ogliaro, F.; Bearpark, M.; Heyd, J. J.; Brothers, E.; Kudin, K. N.; Staroverov, V. N.; Kobayashi, R.; Normand, J.; Raghavachari, K.; Rendell, A.; Burant, J. C.; Iyengar, S. S.; Tomasi, J.; Cossi, M.; Rega, N.; Millam, J. M.; Klene, M.; Knox, J. E.; Cross, J. B.; Bakken, V.; Adamo, C.; Jaramillo, J.; Gomperts, R.; Stratmann, R. E.; Yazyev, O.; Austin, A. J.; Cammi, R.; Pomelli, C.; Ochterski, J. W.; Martin, R. L.; Morokuma, K.; Zakrzewski, V. G.; Voth, G. A.; Salvador, P.; Dannenberg, J. J.; Dapprich, S.; Daniels, A. D.; Farkas, Ö.; Foresman, J. B.; Ortiz, J. V.; Cioslowski, J.; Fox, D. J. Gaussian, Inc., Wallingford CT, 2009. 
8. Becke, A.D. J. Chem. Phys. 1993, 98, 5648.

9. Lee, C.; Yang, W.; Parr, R.G. Phys. Rev. B. 1998, 37, 785-789.

10. Keresztury, G.; Chalmers, J.M.; Griffith, P.R. (Eds.), Raman Spectroscopy: Theory, in: Hand Book of Vibrational Spectroscopy, John Wiley and Sons Ltd., New York, 2002.

11. Keresztury, G.; Holly, S.; Varga, J.; Besenyei, G.; Wang, A.Y.; Durig, J.R. Spectrochim. Acta A 1993, 49, 2007-2026.

12. Hoffmann, R.; Swenson, J.R.; J. Phys. Chem. 1970, 74, 415-420.

13. Akalin, E.; Akyüz, S. J. Mol. Struct. 1999, 482, 175-181.

14. Reed, A.E.; Curtiss, L.A.; Weinhold, F. Chem. Rev. 1988, 88, 899-926.

15. Foster, J.P.; Weinhold, F. J. Am. Chem. Soc. 1980, 102, 7211-7218.

16. Weinhold, F.; Landis, C.R. Valency and Bonding: A Natural Bond Orbital DonorAcceptor Perspective, Cambridge University Press, New York, 2005.

17. Thompson, H.W.; Torkington, P. J. Chem. Soc. 1945, 640-645.

18. Glendening, E.D.; Badenhoop, J.K.; Reed, A.E.; Carpenter, J.E.; Bohmann, J.A.; Morales, C.M.; Weinhold, F. NBO 3.1, Theoretical Chemistry Institute, University of Wisconsin, Madison, 2001.

19. Jamróz, M.H., Vibrational Energy Distribution Analysis VEDA4, Warsaw, 2004.

20. Wilson, E.B. Phys. Rev. 1934, 45, 706-714.

21. Wilson, E.B.; Decius, J.C.; Cross, P.C. Molecular Vibrations: The Theory of Infrared and Raman Vibrational Spectra, Dover Publications, Inc., New York, 1955.

22. Varsanyi, G., Vibrational spectra of benzene derivatives, Academic Press, New York, 1969.

23. Ravikumar, C.; Hubert Joe, I.; Sajan, D. Chem. Phys. 2010, 369, 1-7.

24. Anjaneyulu, A.; Ramana Rao, G. Spectrochim. Acta A. 1999, 55, 749-760.

25. Ravikumar, C.; Hubert Joe, I.; Jayakumar, V.S.
Chem. Phys. Lett. 2008, 460, 552-558.

26. Ravikumar, C.; Hubert Joe, I. Phys. Chem. Chem. Phys. 2010, 12, 9452-9460.

27. Green, J.H.S.; Harrison, D.J. Spectrochim. Acta A 1976, 32, 1265-1277.

28. Sathyanarayan, D.N., Vibrational spectroscopytheory and applications, New age International (P) Ltd., New Delhi, 2004.

29. Kolev, T. J. Mol. Struct., 1995, 349, 381-384.

30. Rostkowska, H.; Nowak, M.J.; Lapinski, L.; Bretner, M.; Kulikowski, T.; Leimage, A.; Adamowicz, L. Spectrochim. Acta A, 1993, 49, 551-565.

31. Yadav, R.A.; Sing, I.S. Indian J. Pure Appl. Phys. 1985, 23, 626-631.

32. Zierkiewicz, W.; Michalska, D.; Huyskens, T.Z. J. Phys. Chem. A, 2000, 104, 11685-11692.

33. Varsanyi, G., Assignments for vibrational spectra of seven hundred benzene derivatives, Adam Hilger, Mooney, 1974.

34. Colthup, N.B.; Daly, L.H.; Wiberley, S.E., Introduction to Infrared and Raman Spectroscopy, Academic Press, London, 1964.

35. Stephens, P.J.; Jalkanen, K.J. J. Chem. Phys. 1989, 91, 1379-1382.

36. Calaminici, P.; Jug, K.; Köster, A.M. J. Chem. Phys. 1998, 109, 7756-7759.

37. Colwell, S.M.; Murray, C.W.; Handy, N.C.; Amos, R.D. Chem. Phys. Lett. 1993, 210, 261-268.

38. McDowell, S.A.C.; Amos, R.D.; Handy, N.C. Chem. Phys. Lett. 1995, 235, 1-4.

39. Hermann, J. P.; Ricard, D.; Ducuing, J. Appl. Phys. Lett. 1973, 23, 178-181.

40. Tommasini, M.; Castiglioni, C.; Del Zoppo, M.; Zerbi, G. J. Mol. Struct. 1999, 480, 179-188.

41. Nakano, M.; Shigemoto, I.; Yamada, S.; Yamaguchi, K. J. Chem. Phys. 1995, 103, 4175-4181.

42. Delgado, M.C.R; Hernández, V.; Casado, J.; Navarrete, J.T.L.; Raimundo, J.-M.; Blanchard, P.; Roncali, J. J. Mol. Struct., 2003, 651, 151158. 